IOSR Journal of Pharmacy

e-ISSN: 2250-3013, p-ISSN: 2319-4219, www.iosrphr.org

Vol. 2, Issue 6, Nov-Dec. 2012, PP. 35-44

\title{
A synthesis of Programmatic Response to HIV/AIDS Pandemic in Kenya: Which way forward?
}

\author{
Timothy C. Okech ${ }^{1}$, Evans Wekesa Mukuusi ${ }^{2}$ \\ ${ }^{I}(P h D)$, Asst. Professor of Economics, Chandaria School of Business United States, International University \\ (USIU) \\ ${ }^{2}$ PhD Student at Jomo Kenyatta University of Agriculture \& Technology (JKUAT)
}

\begin{abstract}
The HIV epidemic in Kenya peaked in the late 1990s with an overall prevalence rate of over $14 \%$. With various iniatives implented, currently the prevalence rate is estimated at $6.3 \%$ in the age group 15-49 years. This notwithstanding, incidence remains high at 132,000 adults and 34,000 paediatric cases annualy. A total of I.5million cases of HIV have been reported to date. With improved diagnostic capacity available across the country more than 800,000 people require treatment and yet only slightly more than 400,000 are currently receiving care and support from all the resources available in the country leaving a large gap. The bulk of the funding for the fight against HIV/AIDS in Kenya comes from the development partners (87\%), leaving only a total of $13 \%$ from government and other local sources. This scenario is likely to worsen as partners become more constrained following international recessions and donors' change in priority package. In this regard, the country has to devise innovative ways of raising revenue domestically to enhance sustainability for HIV financing both in the short term and long term. Various innovative financing strategies are proposed based on the review. Among these include establishing a Trust Fund, introducing a small levy on passenger air ticket, mobile telephone services and remittances from the Diaspora abroad. Others include floating a HIV bond and as well as establishing lotteries specifically for HIV/AIDS.
\end{abstract}

Keywords—Pandemic, Trust Fund, Remittances, Levies, Private Public Partnership, HIV Prevalence rate

\section{I.1 Background}

\section{INTRODUCTION}

HIV/AIDS pandemic is a worldwide problem featuring prominently at global, national, society and household level. Its management is one of the most urgent tasks facing humanity today and the biggest challenge that no country either developed or developing has overcome. There is evidence however that a lot can be done to reverse the situation. Despite now being in its third decade and yet considered to be in its early phase, HIV/AIDS has not shown signs of abating. Contemporary global statistics indicate that currently almost 40 million more were infected in 2004, and more than 3 million people died of Aids that year that is more than ever before and more than from any other infection. Over 2 million children are living with HIV while 15 million have been orphaned by the epidemic. In addition millions of children have been made vulnerable by the illness of parents and family members (HIV/ AID Draft Final Report: UN Millennium Project 2004). HIV/AIDS takes different forms in different communities, countries and regions. At the same time prevalence rates and response to the epidemic differ from one country to another.

Whereas the first cases of HIV/AIDS were diagnosed in the West in the early 1980s, today SubSaharan Africa (SSA) remains the most devastated region in the World. In 2003, UNICEF reported more than 11 million African children under the age of 15 years as orphaned by the pandemic. In the report, it was projected that by 2010 there will be about 20 million children in SSA who will have lost at least one parent to AIDS, bringing the total number of orphans to 42 million. In the worst affected countries of Southern Africa (Botswana, Lesotho, Swaziland and Zimbabwe) more than one in five children will be orphans by 2010. The situation is worsening every day and as put by UN Special Envoy for HIV/AIDs in Africa (January 2004) in most countries in Sub-Saharan Africa "grandparents bury their children and sometimes their grandchildren before they themselves are buried". Experts contend that while average prevalence may be levelling off in the region, the worst of mortality and its social and economic consequences are yet to come. In other countries, the epidemic among the vulnerable groups is growing at an alarming rate (for example Russia, India, China and South East Asia) while in Latin America and the Caribbean, the epidemic continues to evolve but seems relatively stable. Although some national governments are increasingly confronting the challenges of HIV/AIDS, a few others still continue to deny its significance or even its existence within its borders. As a result, policy makers at the local level must be guided by the best possible information on local conditions while 
at the same time incorporating the lessons learned from neighbouring countries and other regions. There is still hope since countries like Brazil, Senegal, Thailand and Uganda have shown that the spread of HIV can be stemmed.

In Kenya, the burden of HIV/AIDS continues to increase and requires urgent and well-targeted multisectoral approach. According to the 2003 National HIV surveillance report, HIV prevalence among adults aged 15-49 years stood at $9.4 \%$ translating into 1.7 million people. Similarly, the 2003 Kenya Demographic and health Survey (KDHS) reported a national prevalence of $6.7 \%$ translating to 1.2 million people. The prevalence levels reported in the two reports clearly show that the probability of many more Kenyans getting infected unless something is urgently done. HIV/AIDS affects various population groups in various ways. On one hand, adults aged 20-49 years who represent the economically active population continue to be infected. The KDHS of 2003 indicated that rural areas have half the HIV prevalence of urban areas. Children under 5 years include nearly 100,000 cases resulting from mother-to-child HIV transmission (MTCT), and between $30 \%-40 \%$ of all infants delivered by infected mothers become infected. As a result, the impact of HIV/AIDS continues to be felt in many sectors in the economy. For instance, in many of the country's general hospitals, HIV/AIDS patients occupy half of hospital beds available. In the education sector, teachers are dying faster than they can be replaced, while students continue to drop out of school to either care for the sick or surviving young siblings as well as the dying parents.

The business sector is not spared either as statistics show that the private sector absorbs an average of HIV/AIDS costs per employee of approximately US $\$ 120$, representing about $8 \%$ of company profits. It was estimated that the average firm in Kenya will be experiencing a total annual HIV/AIDS costs in excess of US $\$ 403000$ by the end of 2005 (Kenya National HIV/AIDS Strategy Plan 2000- 2005). Furthermore, it was estimated that three people die of AIDS every five minutes and 200,000 urgently need antiretroviral drugs but only 12,000 can afford. As a result the disease is costing Kenya more than Ksh.200 million daily (KDHS 2003). Currently, about $80 \%$ of the expenditure for HIV and AIDS in Kenya comes from international sources. Although the HIV response in the country has recorded increasing financial resources from development partners future funding for the AIDS response is increasingly uncertain as a result of changing donor priorities and continuing global financial and economic troubles. Most notably, the Clinton HIV/AIDS Initiative (CHAI) has said it will discontinue support for pediatric ARVs and second-line treatment in 2011; PEPFAR has capped the number of patients it will support to 190,000 patients for next couple of years; and MSF has been transferring its facilities and patients to the government in its phase-out plan. The implication of these developments will be an increasing financing gap. It is therefore particularly worrying that some donors have recently indicated that they want to stabilise, and subsequently decrease, their contributions to the AIDS Response

\subsection{Situation Analysis}

From the documents of National AIDS Control Council (NACC) and findings of modeling projections, a total of $1,743,814$ cases of HIV have been reported up to end of 2010. Figure 1.1 provides the rising pattern of the epidemic with no evidence of leveling off probably because of new infections and lack of universal coverage.

Figure 1.1: Trend in number HIV positive persons in Kenya

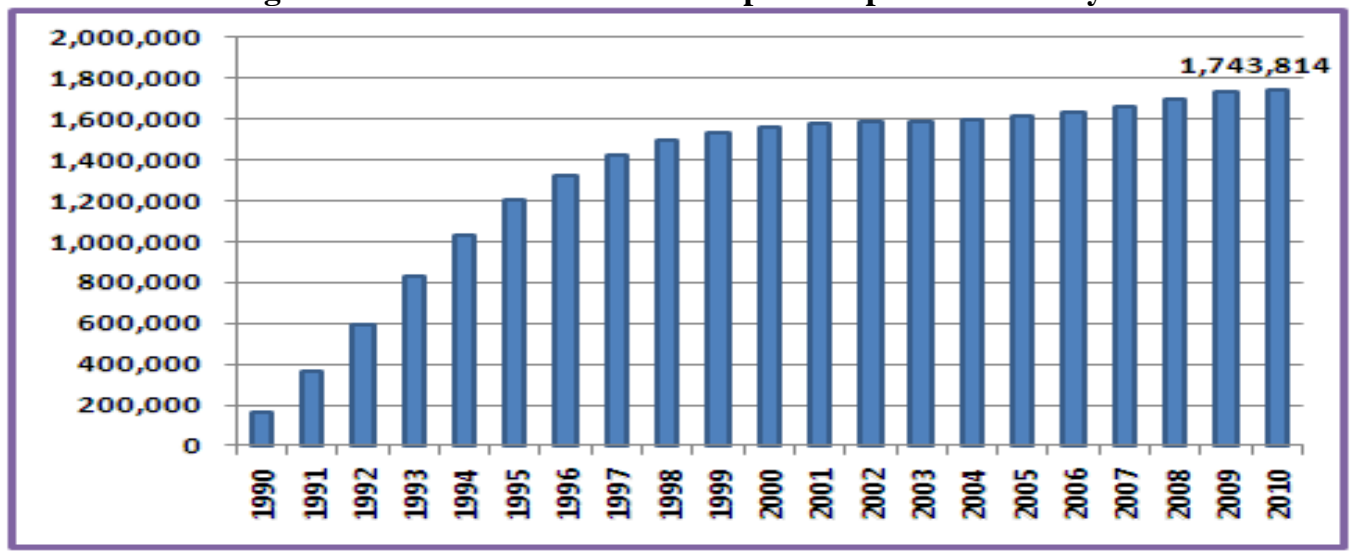

\section{Adapted from John Stover, 2010}

In terms of gender, Muga (2011) noted that the epidemic has currently affected more women than men. For instance, in the 2008/2009 DHS, the HIV prevalence rate for women was estimated at $8 \%$ compared to $4.3 \%$ for men. This rate is however lower than the rates reported in the KDHS of 2003 where the prevalence rate was 
estimated at $8.8 \%$ and 5.5 for women and men, respectively. In both scenario, it is clear that women are most affected that men. Since women are most affected, it also follows that children are equally affected implying that special interventions targeting women and children as part of the most at risk populations (MARPs) is critical. In terms of geographical distribution in the country, there is evident that no part of the country is spared with Nyanza toping the list at $13.9 \%$ followed by Nairobi at $7.0 \%$, Western at $6.6 \%$. These rates compares with the all above the national average estimated at 6.3\% (KDHS, 2008; Muga, 2011).

The epidemiological analysis and modeling from the Modes of Transmission (MOT) study of 2010 revealed that $80 \%$ of new infections in Kenya occur through heterosexual partnerships. In the report, it was noted that the infections are influenced by prevalent cultural and behavioral practices, most notably male circumcision and multiple concurrent relationships. Similarly, the number of women in need of costlier HAART, both to stay alive and to prevent transmission of the infection to their infants, will have increased substantially (UNAIDS, 2010). Similarly, tuberculosis has assumed a higher epidemiological significance in the country since the advent of HIV/AIDS. It is estimated that it carries an annual risk of infection of $1.2 \%$ or about 480,000 new cases (GoK, 2009; Muga, 2011). In addition, an estimated 60\% of HIV cases are co-infected with tuberculosis while notification rates are low at less than $20 \%$. Notwithstanding this, the number of HIV+ women has increased over years from less than 40,000 in 1990s to about 100,000 in 2010. This number is expected to increase to almost 120,000 by 2015 (Muga, 2011). On the other hand, mothers in need of prevention of mother to child treatment (PMTCT) is equally high estimated at 80,000 in 2010 and expected to increase to over 90,000 women in 2015. Additionally, the number of children in need of ARTs is estimated to rise to 764,805 in 2015 up from 416,902 in 2008 representing $55 \%$ increase over a period of seven years only.

\subsection{Effects of the Pandemic}

In the recent years, the death rate from AIDS was estimated at 150,000 per year (NACSOP, 2005). In this report, it was noted that AIDS has lowered life expectancy, deepened poverty in the country, reduced economic growth, exacerbated hunger, and worsened basic health indicators (NACC, 2011). The epidemic is also considred the main cause of a sharp deterioration of basic health indicators, especially in the period between 1998 and 2003, when the epidemic was at its peak. In 2009, an estimated 1.2 million children in Kenya had lost one or both parents to AIDS. Economically, a child with one or more HIV-infected parents is significantly less likely than other children to be in school, more likely to be underweight, and less likely to receive basic medical care (NACC, 2011; Muga, 2011). The HIV and AIDS pandemic is now a global crisis and constitutes one of the most formidable challenges to development and social progress. It is eroding decades of development gains, undermining economies, threatening security and destabilizing societies.

HIV/AIDS profoundly disrupt the economic and social bases of families. It mainly affects people in their prime years of life, the hardest hit being those in the productive ages of between 15 and 60 years. The death of parents has left 1.5 million children as orphans under the care of grandparents/guardians who may not have the capacity and skills to look after them well. It is also affecting the fundamental capacities and rights of staff at the workplace, particularly with respect to discrimination, stigmatization and care and support of those living with and affected by HIV and AIDS. This has also led to high dependency a rate which aggravates problems associated with the already widespread poverty. Illnesses and deaths associated with HIV and AIDS has enormously impacted negatively on the Ministry's service delivery. Budgetary resources allocated for the provision of medical services are hardly enough to cater for the increasing cases requiring care and support of those infected and affected. Kenya also suffered economically as HIV/AIDS reduced productivity of labor as skilled personnel died of AIDS related complications. There was also an increase in poverty levels caused by death of breadwinners at the individual family household. The high mortality and morbidity due to HIV/AIDS increased the cost of providing medical care with health facilities being over-stretched due to many AIDS patients who were being catered for.

\subsection{Policy Response}

\section{PROGRAMMATIC RESPONSE TOWARDS THE PANDEMIC}

To meet the challenge of the HIV/AIDS epidemic in the country the government of Kenya approved Sessional Paper No.4 on AIDS in Kenya in September 1997. This was a clear intent of political will on part of the government to not only support effective programmes to control the spread of AIDS but also to protect the human rights of those with HIV/AIDS and to provide care for those infected and affected by HIV/AIDS. The goal of the Sessional paper was to provide policy framework within which AIDS prevention and control efforts will be undertaken. This strategic framework is considered to be in line with the recommendations of the Millennium Development Goals namely i) to give direction on how to handle controversial issues while taking into account prevailing circumstances and social cultural environment; ii) to provide enable the government to play the leadership role in AIDS prevention and control for a multi-sectoral approach, necessitating involvement from a diversity of actors; and iii) recommend an appropriate institutional framework for effective management 
and coordination of HIV/AIDS programme activities. The Sessional paper recognized the fact that responding to the HIV/AIDS crisis would require strong political commitment at the highest level as well as the implementation of a multisectoral prevention and control strategy with priority focus on young people. Others included mobilization of resources for financing HIV prevention, care and support, and establishment of a national AIDS Control Council to provide leadership at the highest level possible.

The Plan was linked to the National Development Plan (NDP) 1997-2001 and the National Poverty Eradication Plan (NPEP) of 1997-2001. The overall theme of the policy document was social behavior change to reduce HIV/AIDS and Poverty. Key components in the policy document AIDS as well as mechanisms revolved around the mitigation of social-economic impact at individual, family, community, sectoral and national levels. This approach facilitates the investment of significant amounts of resources at district, community and household levels where both the main determinants and the main impact of the disease lie. The Five priority areas highlighted in the plan include prevention and advocacy, treatment, continuum of care and support, and mitigation of social economic impacts. Others were monitoring and evaluation, and research, management and coordination. In 1999, the government declared HIV/AIDS a national disaster, and subsequently established the National Aids Control Council (NACC) under the Office of the President to coordinate a multisectoral national response. In 2002, the Council launched the National HIV/AIDS strategic plan for $2000-2005$ which it had initiated in 2000. Subsequent public debates increased awareness and governmental commitment at the highest levels. The establishment of NACC and NASCOP in the Ministry of Health provided the national institutional framework for liaison and coordination of activities to combat HIV/AIDS. The establishment of Constituency HIV/AIDS Committees further has added yet another layer in the fight against the pandemic. Cabinet Ministers have also formed committees to give impetus to the multisectoral national response.

The strategic plan has successfully been implemented, thanks to the commitment of the government, development partners, civil society organizations including FBOs and the private sector.These HIV/AIDS stakeholders have put in place effective HIV/AIDS programmes/interventions that have seen the prevalence fall significantly from $14 \%$ experienced in 1998 to $7 \%$ in 2005 . Some of these interventions include promotion of safer sexual practices including the use of condoms; early diagnosis and treatment of Sexually Transmitted Infections, provision of ART to PLWHAs, treatment of Opportunistic Infections, ensure that there is safe blood for transfusion. Other interventions initiated and implemented include behavioral change communication; setting up a VCT centres, capacity building (training) of health personnel on the use of Anti Retroviral Drugs ; and development of policy, guidelines and strategies to enhance awareness and education. NACC has been coordinating the activities while other stakeholders such as private sector, government ministries/departments/parastatals, civil society (CBOs, FBOs and NGOs) have been implementing the HIV/AIDS activities. Although major progress in the fight against HIV has been achieved over time, it is important to note that the country has never achieved universal access to HIV and AIDS services. For instance, the number of people receiving ART rose 34\% in 2009, the resultant ART coverage was $70.5 \%$ by end of December 2009. However, under new treatment guidelines, this only represented $48 \%$ of those who were medically eligible for antiretroviral in 2009.

In September 2003, an important step was made in establishing a rights-based framework for effective action on AIDS. This was the time when the Government approved legislation making it illegal to engage in employment discrimination on the basis of a person's HIV status. The law also prohibited insurers from withholding services to people living with HIV or from imposing discriminatory premiums on HIV-infected individuals. In 2006, Kenya enacted the HIV/AIDS Prevention and Control Act. The law formally protects the rights of people living with HIV, prohibits mandatory HIV testing, and authorizes various measures to mitigate the epidemic's impact. A declaration of 'Total War on AIDS' was one of the first acts of President Kibaki that saw the bringing together of an ecumenical group of religious leaders in this fight against HIV. Formal policies and guidelines were in the process developed to support programme planning and implementation with respect to specific aspects of the AIDS response. Areas covered by different guidelines include antiretroviral therapy, voluntary counseling and testing, sexual and reproductive health services for young people, and AIDS education in primary school settings (NACC, 2011). In the last 10 years HIV-related health services have expanded dramatically including the widespread availability of testing and counseling, and treatment with antiretroviral drugs, both to prevent mother-to-child transmission and to improve health and prolong life for people with advanced HIV infection and AIDS.

The Kenyan government is a signatory to the UN resolution calling for a national plan of action for orphans which was supposed to be in place by 2003. In this regard, the Ministry of home affairs together with a parliamentary committee for orphans has been leading the way towards that goal. Similarly, the clerk to the National Assembly formed a parliamentary steering committee on OVC to spearhead discussion on way forward. For the health sector to effectively respond to the epidemic there is need for more resources to be channeled to innovative interventions such as expanding early diagnosis and including counseling on behaviour 
change aimed at reducing the spread of HIV. Though in Kenya over $90 \%$ of the people are aware of the nature and transmission of HIV/AIDS, the challenge has been to translate this awareness into preventive behaviour among the sexually active and high-risk population. High risk priority groups include adolescents (in and out of school), women and girls between 15- 49 years, commercial sex workers and long distance drivers, security forces, fishing and mining communities, population in places like the slums as well as nomads and beach communities. Other high-risk categories may be identified depending on socio-cultural, geographical and other specific factors. The government has adopted various approaches to the fight against malaria nationwide with greatest attention given to the prone areas. Long-Lasting Insecticide Treated (LLIT) bed nets as well as treatment for malaria can now be obtained in government hospitals and health centers at subsidized and affordable cost.

Despite the successes recorded in the fight against HIV/AIDS, there are many challenges that impede successful fight against the scourge. These challenges include first, new infections whereby the fight against HIV/AIDS faces the challenge of new infections due to the youthful population and the fact that there are many people currently infected. Two, high death rates occasioned by high HIV prevalence rate. Although HIV prevalence has reduced from $14 \%$ in the 1990s to 7 percent currently, the high HIV prevalence is currently causing death to over 140,000 Kenyans per year and over 1.7 orphans. There is currently 1.4 million people living with the virus and it is expected that a significant number may die from HIV/AIDS related complications in the next 2-3 years $(\mathrm{GoK}, 2010)$. The third challenge is poverty as productivity declines and individual's income is reduced due to high treatment costs. Poverty levels are worsened when a breadwinner succumbs to AIDS. As a result of decline in productivity and income levels, economic growth and development is negatively affected. It is estimated that HIV/AIDS will reduce per capita income by $14 \%$ and economic growth by $10 \%$ by 2010 if the current high HIV prevalence is not checked. The fourth challenge is high cost of treatment which has led to an increase in the cost of treatment.

Finally, the high cost of ARVs is a challenge as most PLWHAs do not have access to quality ARV due to high level of poverty while the cost of ARVs is still high especially the branded ones. Although there exists generic ARVs at Ksh 500/= in the provincial health facilities, this cost is still high to most PLWHAs, majority of who live below the poverty line of less than us $\$ 1$ per day. The high level of poverty especially denies the PLWHAs even access to basic needs including food thereby making ARVs ineffective even if they get access to free ARVs. Others relate to discrimination and resource gap. In terms of discrimination and stigma, in some communities PLWHAs are discriminated against thus making them shy away from disclosing their HIV status. Regarding resource gap, it is estimated that the total financing requirement of implementing the new KNASP has increased from Kshhs. 25 billion in 2005/6 to Kshs. 45 billion in 2009/2010, of this total 30\% is allocated to prevention, $27 \%$ to improving quality of life of those infected and affected and 16\% to support services. The greatest challenge faced by Kenya as a country is how to mobilize additional resources during the remaining years of the KNASP in order to achieve its objectives. In spite of this effort, HIV/AIDS is a threat to the entire Kenyan population and especially the young who are also the most economically active.

\subsection{Financing of HIV/AIDS in Kenya \\ 2.2.1 General Financing}

Table 1.1 shows that the total public spending on health in absolute terms has increased steadily from 2000/01 through 2009/10. The total expenditure rose from about Ksh 12 billion in 2000/01 to about Ksh 47 billion in 2009/10. As shown in the table, the percentage of public health spending in the total government expenditure was over $7 \%$ in early 2000s, the percentage declined to about $6 \%$ in the late part of the 2000 s $(\mathrm{GoK}$, 2009).

Table 1.1: Public health spending 2000/01 - 2009/10

\begin{tabular}{|lll|}
\hline $\begin{array}{c}\text { Total public } \\
\text { (Ksh million) }\end{array}$ & health expenditure & $\begin{array}{l}\text { Total public health expenditure as } \\
\text { \% of government expenditure }\end{array}$ \\
\hline $\mathbf{2 0 0 0 / 0 1}$ & 12,072 & $7.2 \%$ \\
\hline $\mathbf{2 0 0 1 / 0 2}$ & 15,234 & $9.0 \%$ \\
\hline $\mathbf{2 0 0 2 / 0 3}$ & 15,351 & $8.3 \%$ \\
\hline $\mathbf{2 0 0 3 / 0 4}$ & 16,441 & $7.0 \%$ \\
\hline $\mathbf{2 0 0 4 / 0 5}$ & 19,158 & $6.1 \%$ \\
\hline $\mathbf{2 0 0 5 / 0 6}$ & 23,007 & $7.4 \%$ \\
\hline $\mathbf{2 0 0 6 / 0 7}$ & 27,472 & $5.8 \%$ \\
\hline $\mathbf{2 0 0 7 / 0 8}$ & 32,354 & $6.4 \%$ \\
\hline $\mathbf{2 0 0 8} / \mathbf{0 9}$ & 34,845 & $6.0 \%$ \\
\hline
\end{tabular}




2009/10 $47,012 \quad 6.9 \%$

\section{Source: Ministry of Health's PER 2007, 2008, 2010}

Although the government also committed increasing allocations to the health sector, National Health Accounts reports have shown that households, through out of pocket expenditure, are the largest source of funds for health care in Kenya estimated at 35\% of total health expenditure (GoK, 2008). A portion of this household contribution is spent on financing HIV and AIDS services. For instance, in 2001/02, this expenditure was estimated at Ksh 2.61 billion representing $26.30 \%$ of total HIV spending in the country. In 2005/06, this however reduced to Ksh 4.24 billion representing $22.5 \%$ (GoK, 2008).

\subsubsection{HIV/AIDS Financing}

Although the demographic data show that the country has not achieved universal coverage, nevertheless the national response to the epidemic has seen increase in financial resources in the last decade (Muga, 2011; GoK, 2009; GoK, 2010). Table 1.2 shows the trend in AIDS spending in Kenya during the fiscal years 2000/01 through 2008/09.

Table 1.2: Trend in AIDS spending

\begin{tabular}{|lcc|}
\hline Financial Year (FY) & Total spending (Ksh million) & $\begin{array}{l}\text { Total spending (US \$ } \\
\text { million) }\end{array}$ \\
\hline $\mathbf{2 0 0 0 / 0 1}$ & 7,680 & 109.71 \\
\hline $\mathbf{2 0 0 1 / 0 2}$ & 9,011 & 128.72 \\
\hline $\mathbf{2 0 0 2 / 0 3}$ & 11,702 & 167.17 \\
\hline $\mathbf{2 0 0 3 / 0 4}$ & 13,590 & 194.14 \\
\hline $\mathbf{2 0 0 4 / 0 5}$ & 12,880 & 181.67 \\
\hline $\mathbf{2 0 0 5 / 0 6}$ & 11,511 & 162.35 \\
\hline $\mathbf{2 0 0 6 / 0 7}$ & 29,665 & 418.58 \\
\hline $\mathbf{2 0 0 7 / 0 8}$ & 43,505 & 659.87 \\
\hline $\mathbf{2 0 0 8} / 09$ & 53,153 & 687.26 \\
\hline
\end{tabular}

Source: Kioko et al. (2004), Odundo et al. (2008) UNGASS 2010, Indicator 1 report

As shown in Table 1.2, total expenditure on HIV and AIDS expenditure has been rising from about Ksh 7.7 billion in 2000/01 to Ksh 53 billion in 2008/08. The AIDS spending rose seven-fold between 2000-2001 and 2008-2009, including 18\% in 2008-2009 alone. The bulk of this funding comes from development partners (about 87\%) while government contribution is about 13\% (GoK, 2009; GoK, 2010). The government contribution includes indirect funding through the Ministry of Health. Otherwise, earmarked financing from government makes up about $3 \%$ of the total spending on HIV and AIDS activities in the country. In the Kenyan National Health Accounts (NHA), it is estimated that $5.2 \%$ of the national budget was spent on health in 2005/06 (Government of Kenya \& Health Systems 2020 Project, 2009). The HIV sub accounts of the NHA shows that within the health budget $6.4 \%$ was allocated to HIV/AIDS representing

Although the HIV response in the country has recorded increasing financial resources from development partners, future funding for the AIDS response is increasingly uncertain as a result of changing donor priorities and continuing global economic crises. Most notably the Clinton HIV/AIDS Initiative (CHAI) will discontinue support for pediatric ARVs and second-line treatment in 2011; PEPFAR has capped the number of patients it will support to 190,000 patients for next couple of years; and MSF has been transferring its facilities and patients to the government in its phase-out plan. The implication of these developments will be an increase in the financing gap as the commitment in terms of financing falls short of these financing requirements as summarized in table 1.3.

Table 1.3: Expected financial contributions (Ksh) from GOK and development partners

\begin{tabular}{|c|c|c|c|c|}
\hline & 2010/11 & 2011/12 & $2012 / 13$ & 2013/14 \\
\hline Domestic & \multicolumn{3}{|c|}{$1,821,468,480$} & \multirow[t]{2}{*}{$1,796,225,280$} \\
\hline & $1,897,101,440$ & \multirow{2}{*}{\multicolumn{2}{|c|}{24.536 .971 .680}} & \\
\hline International & & & & $22,872,971,68$ \\
\hline & $24,536,971,680$ & & $22,872,971,680$ & 0 \\
\hline Global Fund (R7) & & \multicolumn{2}{|l|}{$2,170,038,720$} & $2,231,357,920$ \\
\hline & $1,525,160,880$ & \multirow{2}{*}{\multicolumn{2}{|c|}{$28,528,478,880$}} & \\
\hline Total & & & & $26,900,554,88$ \\
\hline
\end{tabular}

www.iosrphr.org

$40 \mid \mathrm{P}$ a g e 
A syntheses of programmatic response to hiv/aids pandemic in Kenya: which way forward?

$$
27,959,234,000
$$

$26,954,425,600$

Source: NACC Gap Analysis, 2010.

As indicated in the table, it is clear that the country faces a serious sustainability problem in combating the HIV. This calls for initiation of innovative sustainable ways of raising additional funds to fight the epidemic. As envisaged in the Vision 2030, should Kenya succeed in becoming a middle-income country by 2030, it may no longer be viewed as eligible to continue receiving large sums of international aid to combat HIV and meet other primary health care needs. As the country works towards universal access to HIV prevention, treatment, care and support, the gap between available resources and actual needs is projected to increase in the coming years. In this regard, various alternative sources of HIV/AIDS funding are inevitable. In the next sub-section, a synthetic review of possible sustainable financing mechanisms is reviewed.

\subsection{Introduction}

\section{POSSIBLE ALTERNATIVE FINANCING MECHANISMS}

To reverse the situation, sufficient sustainable financial resources are required, and equally important, the available resources must be used as efficiently as possible. In these regard, the country has to devise innovative ways of raising revenue domestically to enhance sustainability for HIV financing both in the short run and long run. These range from enrolling more households to be members of National Health Insurance Fund (NHIF); establishing a trust fund; introducing a small levy on passenger air ticket and mobile telephone services, among other initiatives. In this sub-section, some of these initiatives are reviewed based on existing literature.

\subsection{Budgetary Allocation}

It is necessary for the Kenya government to legally establish an institution that would manage HIV pandemic in the country. This would in the process allow for the creation of a specific budget line for the management of the pandemic. Currently, the government revenue is around 19\% of GDP, which is approximately average for sub-Saharan Africa countries. This ratio can be expected to rise slowly as the percapita GDP rises given the country's economic performance, in line with the experience of other countries and Kenya's growth strategies under 2030 vision. Compared to the Abuja Declaration target of $15 \%$ of total government budget allocated to health, Kenya's public health expenditure currently stands at about $8 \%$, hence, if backed by the right political will, Kenya's presently under-performing economy and revenue base is suggested to be capable of substantially increasing its share of financing the HIV burden. Besides, there are a number of (smaller, poorer) countries that maintain a revenue share substantially above the average level examples include Malawi, Gambia, Ghana, Zimbabwe and Lesotho. If the experience of these countries is used as a benchmark, this would imply that Kenya could possibly reach a level of about $25 \%$ without major economic distortion as well as crowding out of private sector. This thus requires necessary political and leadership commitment. Thus, in order to achieve this and ensure direct linkages to Vision 2030, the Government of Kenya has set out a plan to develop a strategy and relevant policies to support the health and HIV financing through sustainable and strengthened domestic resources.

\subsection{Establishing HIV/AIDS Trust Funds}

A trust fund is expected to operate as a public private partnership (PPP) where in all stakeholders are expected to contribute resources specifically for HIV/AIDS. For this to be effective, the necessary legal framework has to be put in place regarding the contribution and management of the resources devoid of government perennial bureaucracy. Similarly, within the legal framework, an institution has to be established with the necessary clear mandate regarding the fund. Various HIV/AIDS trust funds have been implemented in many developing countries some reporting success stories. In Zimbabwe, for instance, The Zimbabwe National AIDS Trust Fund (ZNATF) was financed by a levy of $3 \%$ on the taxable income of individuals and firms. The levy was reported to be highly unpopular, due to a combination of resentment at the effective increase in tax rates at a time when incomes were under stress, as well as concerns about transparency and accountability in the use of ZNATF resources.

In South Africa, the National AIDS Trust was established in 2002 to support the South African National AIDS Council (SANAC). However this is an advisory body and has no statutory status. It is a funded scheme and the objective of the board of trustees is to secure funding for SANAC activities (South Africa Department of Health, 2006). Given that countries have trust funds in place, it will be necessary that before considering this as a source of financing, it will be necessary to undertake a comprehensive analysis on how these were formed and how they have been managed over the years. 


\subsection{Dormant account funds and unclaimed Assets}

Unclaimed assets are properties that have gone unclaimed for a defined time period. These could be i) financial - including inactive customer bank accounts, unclaimed income from stocks and shares, and unclaimed retirement benefits; and ii) non-financial, such as land. In Kenya, studies show that there are a number of dormant accounts held in Kenya with majority being accounts in commercial banks, although there is also some land unused. In this regard, it is necessary to merge these funds into a single account and invest the funds whilst tracking down the owners. The interest would be collected by the GoK to pay for social services, with a fraction directed towards combating HIV/AIDS. Like in the case of trust fund, there will be need to establish necessary legal framework that will i) pay attention to the management of information and the identification of unclaimed assets according to prescribed definitions; and ii) the establishment of a central reclaim fund and an unclaimed assets agency to regulate and manage the assets As noted in Lievens et al (2011), unclaimed financial assets may never be restored to their rightful owners or beneficiaries primarily due to death, lack of tracking mechanisms or legal instruments. This financing option has the potential to increase government revenues without raising taxes. To ensure that any negative macroeconomic consequences are mitigated, it will be important to know exactly how dormant funds are treated by the various institutions. This will allow a better comprehension of the macroeconomic impact of taking these to invest for government purposes. The effectiveness of this requires a legal framework that will govern the process including the establishment of a regulatory agency that will govern the same.

\subsection{Issuance of HIV Bond}

An AIDS-specific government bond could be issued at a lower rate of interest than other government bonds. Any new borrowing must be set in the context of maintaining a sustainable debt stock. There are no universal rules that set a limit on how much debt a country can incur without facing repayment problems. A country must set its own debt strategy based on a wide range of country specific factors, such as the share of foreign denominated debt, the share of variable interest rate debt and the volatility of the country's economy, government revenues and exports. Nevertheless, there are two sources which can be used for comparison in this instance. Firstly, the IMF/World Bank Debt Sustainability Framework proposes a limit for the Net Present Value (NPV) of external debt of $40 \%$ of GDP (World Bank, 2006).Secondly, the Growth and Stability Pact established a limit on the debt stock of $60 \%$ of GDP for the euro zone countries, though many of the member countries exceeded this ratio even before the financial crisis.

\subsection{Airline levy}

One of the innovative funding mechanisms currently being implemented in a number of countries in Europe and a few in Africa is a solidarity levy on airline tickets. An aviation solidarity levy has been used to help mitigate what are seen as negative impacts of globalization and also provide funds to finance HIV/AIDS treatment. Member countries agree to donate the revenues of a solidarity tax added to on plane tickets to existing national and international development institutions. A levy on airline tickets is both long-term and predictable, as air travel is growing and is expected to continue to grow in years to come. The main advantage of the airline solidarity levy is that it can be implemented in participating countries even if other countries do not wish to participate in the initiative. Some proponents of the initiative argue that the levy will reduce demand for plane tickets and therefore might not generate the expected revenue. However, there is evidence that the price elasticity on demand for plane tickets is low and that the airline industry is not be affected by this additional tax. Further, the levy is to be small relative to the cost of air travel (WHO, 2007).

Kenya has a strong position in East Africa as a regional hub for air travel and freight. Nairobi is a key end destination for tourism and transfer hub for much business in the region and internationally. For example the Kenyan Airports Authority website states that Nairobi Airport - Jomo Kenyatta International (JKIA) - is "served by 49 scheduled airlines. JKIA has direct flight connections to Europe, the Middle East, Far East and the African Continent. Nairobi airport - Jomo Kenyatta International - is the busiest airport in East and Central Africa and the sixth busiest on the entire continent. A study carried out by the Ministry of Tourism in 2006 shows that Kenya was the fifth most popular tourism destination in Africa (Ministry of Tourism and Wildlife, 2006). Indeed the rate of growth in tourism-related activities has been twice as fast as overall GDP in the past five years. Tourism also brings in crucial foreign exchange, indeed revenues from tourism were estimated at over 70 billion KES in 2010.

\subsection{Increasing the private sector's contribution to HIV/AIDS}

Private businesses and companies are seen as an integral part of the fight against the HIV/AIDS pandemic. They have a unique role to play because of their interaction with the age group that are disproportionately affected by the virus and because structures, communications systems and training capacities 
that are already in place can be used for prevention, care and support programmes. Furthermore, businesses and companies are seen as an additional financing source in an environment of limited resource availability. In addition to workplace programmes, some companies go further than their own workplace and advocate for increased engagement in HIV/AIDS work by other companies, sectors, communities, consumer groups and governments through their corporate social responsibility. Private sector contributions can be motivated by a sense of corporate citizenship or by the direct effect that HIV/AIDS has or could have on their business including first, increased costs such as health insurance, sick leave and funeral benefits, as well as recruitment and training of new staff. The second motivation is in terms of reduced productivity caused by increased absenteeism (due to illness or caring for the sick), high staff turnover, loss of intellectual capital and loss of morale. Finally, this could be motivated by a fall in the demand for goods and services as household disposable income falls due to higher health care costs or loss of income.

In a number of high prevalence countries, business coalitions have been formed with the objective of strengthening the private sector response to the epidemic. In Rwanda for instance, Lievens et al (2011) observed that the HIV/AIDS business coalition, "Association du privé et para-étatique dans la lutte contre le VIH/SIDA" (APELAS), was created in 2001 and at that time was funded almost entirely through the World Bank's Multicountry AIDS Programme (MAP). Similarly in in Ivory Coast the Coalition of Enterprises against HIV/AIDS (CECI) was established to promote integrated and effective programmes to fight against HIV, TB and Malaria among companies in the Ivory Coast (Lievens et al., 2011).

\subsection{Imposing a levy on international remittances}

Imposing a levy on international remittances has been identified as a potential revenue source for funding HIV/AIDS, by adding a small fee onto all money transfers from abroad. Remittances can be made through formal and informal channels. Formal channels include domestic and international banks and service providers such as Western Union and Moneygram. Factors affecting their use include high transaction costs which are believed to dampen the scope of money transfers; banking requirements often excluding potential users from accessing banking services; clearance times for money transfers are notoriously long; and stringent exchange controls. On the other hand, informal channels include money carried by migrants themselves, remittances carried by friends and family, or sent through taxis and buses.

The policy option to impose a levy would only impact on the formal sector transactions. This additional cost to transferring money through formal channels may lead to a move from formal to informal channels, with consequent externalities associated with this. It is possible that, if the diaspora are aware that the extra charges are channelled to HIV/AIDS programmes, they will be sympathetic and this could mitigate the shift towards informal remittances. It is clear that remittances provide a crucial source of income for the population. They can be spent on health services, including HIV/AIDS related treatments, and in doing so will contribute to the financing of HIV/AIDS. The proposed levy will be imposed on only formal inward international remittances. A study into the remittance market in Kenya found that remittance services market in Kenya is thriving in terms of both remittance volume and the diversity of the providers, both internationally and domestically.

\subsection{Conclusion}

\section{CONCLUSION AND WAY FORWARD}

Kenya is one of the sub-Saharan countries bearing the highest burden of the HIV and AIDS with the impact of the epidemic felt across the whole country. The bulk of the funding for the fight against HIV and AIDS in Kenya comes from the development partners (87\%), leaving only a total of $13 \%$ from government and other local sources. This scenario is likely to worsen as partners become more constrained following international recessions and change on strategic focus. HIV/ AIDS remains a national disaster and still calls for immediate and sustained action by Government and its partners, private sector individuals and households. The disaster should formally be gazetted by government, to facilitate the creation a specific budget line. Further the budget line should be ring fenced so that the financing gap is addressed and the issue of scale up continuously addressed. Clearly, the scale up path toward Universal access to HIV prevention, care, treatment and support cannot take place without increased financing from domestic, bilateral and multilateral sources.

\subsection{Way Forward}

Management of and eventual decentralization of sustainable treatment, care and support of HIV/AIDS in all areas of the economy is critical for the achievement of vision 2030. Stakeholders in the country including government, private sector, civil society and Diaspora in Kenya and abroad, development partners among others need to come together and develop necessary legal framework that will establish the trust fund as well a legal entity that will manage the resources raised. Similarly, there is urgent need for political commitment and goodwill to increase budgetary allocation towards the health sector in line with the Abuja Declaration. Other 
proposals for sustainable financing of HIV/AIDS that have been proposed include establishing the necessary legal framework that will allow the government to impose levies on air ticket, air time and remittances from the Diaspora. To avoid these initiatives being challenged in the court of law, it is important that the views and suggestions of different stakeholders including the civil society, academicians, and umbrella bodies for workers and employers amongst others are consulted accordingly.

\section{REFERENCES}

[1]. Gelmon L et al. (2009). Kenya HIV Prevention Response and Modes of Transmission Analysis. Nairobi: Kenya National AIDS Control Council.

[2]. Global development finance (2008). Financial flows to developing countries: recent trends and prospects, The World Bank Group.

[3]. GoK (2009a). Kenya Demographic and Health Survey 2008-09. Calverton, Maryland (USA): Kenya National Bureau of Statistics, ICF Macro.

[4]. GoK (2004), Kenya Demographic and Health Survey 2003. Calverton, Maryland (USA): Central Bureau of Statistics, Ministry of Health, ORC Macro.

[5]. GoK (2006). Preparedness for HIV/AIDS service delivery: The 2005 Kenya Health Workers Survey. Nairobi: NASCOP, Ministry of Health.

[6]. GoK (2009b) Kenya National AIDS Strategic Plan 2009/10 - 2012/13 Delivering on Universal Access to Services, Nairobi, Government Printer

[7]. GoK (2009c). National Health Accounts 2005/2006. Bethesda, Maryland (USA): Abt Associates Inc.

[8]. GoK (2010b ), Report of the Technical Working Group on Sustainability for HIVAIDS in Kenya, Nairobi, United States Agency for International Development

[9]. GoK(2010a), Budget Outlook Paper 2011/12 - 2013/204, Nairobi, Government Printer

[10]. Henry J. Kaiser Family Foundation UNAIDS (2010). Financing the Response to AIDS in Low-and Middle-Income Countries: International Assistance from the G8, European Commission and Other Donor Governments in 2009. Menlo Park, California: Henry J. Kaiser Family Foundation.

[11]. NACC (2011) Policy Brief on Sustainable financing of HIV/AIDS in Kenya

[12]. National AIDS Control Council (2009). Kenya National AIDS Spending Assessment: Report for the Financial Years 2006/07 and 2007/08.

[13]. National AIDS Control Council (2009). Kenya National AIDS Spending Assessment: Report for the Financial Years 2006/07 and 2007/08.

[14]. National AIDS Control Council (2009). Kenya National AIDS Strategy Plan 2009/10 - 2012-13: Delivering on Universal Access to Services.

[15]. National AIDS Control Council (2010). UNGASS 2010: United Nations General Assembly Special Session on HIV and AIDS. Country Report - Kenya.

[16]. World Bank (2010). World Development Indicators 2010. Washington DC: World Bank.

[17]. World Bank and UNAIDS (2008), AIDS Strategy and Action Plan (ASAP) Costing Tool v.1.2. Washington DC and Geneva, Switzerland. 